\title{
Comparison of Walleye Egg Survival Following Fertilization at Differing Egg Depths
}

\author{
Matthew J. Ward (Corresponding Author) \\ South Dakota Department of Game, Fish and Parks, Blue Dog State Fish Hatchery \\ 44437 139A Street, Waubay, South Dakota, 57273, United States
}

Tel: 1-605-947-4657Ｅ-mail: matthew.ward@state.sd.us

\begin{abstract}
Brian G. Blackwell
South Dakota Department of Game, Fish and Parks, District Office, 603 East $8^{\text {th }}$ Avenue, Webster, South Dakota, 57274, United States
\end{abstract}

Tel: 1-605-345-3381Ｅ-mail: brian.blackwell@state.sd.us

Received: Dec. 18, 2019 Accepted: Jan. 15, 2020 Published: Jan. 16, 2020

doi:10.5296/ast.v8i1.16260 URL: https://doi.org/10.5296/ast.v8i1.16260

\begin{abstract}
Extruded egg depth during artificial fertilization of walleye Sander vitreus is known to affect egg fertility and has been suspected of contributing to the observed low percent hatch of eggs in South Dakota. Our objective of this study was to determine if walleye egg survival through hatching could be improved by reducing the egg depth in standard pans during fertilization. Survival of walleye eggs extruded to the currently-used depth of $19 \mathrm{~mm}$ was compared to a reduced depth of $7 \mathrm{~mm}$ in standard pans and fertilized with equal amounts $(9 \mathrm{ml})$ of extended semen. Eggs were collected and fertilized during 3 days of each spawning season in 2017 and 2018. Egg survival through hatching was significantly $(P<0.01)$ greater at the $7 \mathrm{~mm}$ depth during 4 of 6 days; there was no difference in egg survival between egg depths during the other 2 days, both occurred in 2017. Our results indicate that reduced egg depth during fertilization will enhance egg survival. The improved survival at the 7-mm depth likely was due to increased fertility resulting from an increased ratio of semen to egg. Although egg survival was higher at the 7-mm depth versus the 19-mm depth, the survival (13-59\%) from each egg taking day was lower than commonly reported $(>65 \%)$ in other states. The lower egg survival South Dakota has experienced suggest that factors other than egg depth may also be hindering fertilization and should be investigated.
\end{abstract}

Keywords: Walleye, Sander vitreus, egg fertilization, egg depth, egg survival 


\section{Introduction}

Due to large popularity of walleye Sander vitreus among anglers (Longmire, 2019), propagation is completed by fisheries agencies throughout much of North America for stock enhancement (Summerfelt et al., 2011). The success of walleye propagation initially hinges upon egg fertilization. Artificial fertilization is commonly achieved through stripping eggs into a dry pan, adding semen, and then water to activate the sperm (Summerfelt et al., 2011). Multiple variables during fertilization can impact walleye egg fertility and survival including the procedures followed by personnel collecting and fertilizing the eggs. A $4 \%$ increase in egg survival was achieved by using three additions of $3 \mathrm{ml}$ of extended semen at 30 second intervals over a one-time addition of $9 \mathrm{ml}$ (Moore, 2003). Whereas, egg depth of extruded eggs was found to have a more pronounced effect on survival with a $21 \%$ increase for eggs fertilized at a depth of $4 \mathrm{~mm}$ compared to $10 \mathrm{~mm}$ (Moore, 2003). Sperm density was found to explain $89 \%$ of the variation in fertilization success with sperm densities of 500/ml yielding $1.0 \%$ fertility while 500 000/ml yielded $90.6 \%$ (Casselman et al., 2006). Further, a sperm to egg ratio of 25 000:1 will produce approximately 70\% egg survival while ratios below 25 000:1 can reduce egg survival to $<20 \%$ (Rinchard et al., 2005).

Fisheries agencies typically achieve 65 to $90 \%$ eye up for fertilized walleye eggs (Bennett and Melby, 1996; Colesante, 1996; Copeland and Wolgamood, 1996). Recently, Nebraska has consistently attained greater than $70 \%$ hatch from their walleye spawning operation (Sweet, 2017). The percent hatch obtained by South Dakota Department of Game, Fish and Parks (SDGFP) has been lower than that of other agencies. Since 2014, percent hatch in South Dakota has been below 50\%. An improvement in the percent hatch could substantially reduce the number of walleye eggs needed to be collected as the egg goal generally exceeds 100 million.

It is believed that the depth of extruded eggs may be contributing to low walleye egg survival observed by SDGFP. The average egg depth used during fertilization in South Dakota is 19 $\mathrm{mm}$ (unpublished data) which is substantially deeper than the egg depths tested by Moore (2003). The objective of this study was to determine if walleye egg survival through hatching could be improved by reducing the extruded egg depth from 19 to $7 \mathrm{~mm}$ during fertilization. A depth of $7 \mathrm{~mm}$ was used because it yielded $77 \%$ egg survival in a previous walleye study (Moore, 2003) and is a 2.7 times reduction in the egg depth currently used in South Dakota artificial fertilization procedures.

\section{Materials and Methods}

\subsection{Gamete Procurement, Fertilization, and Transport}

In 2017, semen was collected from male walleye from Reid Lake (Clark County, South Dakota) on April 13 and extended using procedures described by Moore (1996). Semen from a minimum of five males was pooled before extender was added to the semen. The $\mathrm{pH}$ of the extender solution was 9.0 before semen was added. Eggs were collected from female walleye captured in overnight sets of modified-fyke nets in Mid-Lynn Lake (Day County, South Dakota) on April 14, 15, and 16. Each day newly collected ripe females were measured for 
total length $(\mathrm{mm})$ and wiped dry with a towel prior to eggs being extruded. We attempted to use females of similar size to remove potential differences in egg viability due to female size. Eggs were manually stripped into standard pans $(26.7 \mathrm{~cm}$ diameter by $10.2 \mathrm{~cm}$ deep) with depths of 7 and $19 \mathrm{~mm}$ above the pan bottom marked on the side. Prior to going in the field each day, all vials of extended semen were checked for motility and were kept cool until used.

Eggs were stripped following the procedures outlined by Summerfelt et al. (2011) with an average of 3.0 females being needed per pan to achieve an egg depth of $19 \mathrm{~mm}$ and 1.5 females to achieve an egg depth of $7 \mathrm{~mm}$. Once the desired egg depth was reached, $9 \mathrm{ml}$ of extended semen was added to the top of the eggs along with $1.0 \mathrm{~L}$ of lake water. The eggs and semen were then stirred with a turkey Meleagris spp. feather for $30 \mathrm{~s}$ and then allowed to set for an additional $30 \mathrm{~s}$ before a diatomaceous earth (Perma-Guard, Inc. Bountiful, Utah) solution was added and the mixture stirred for $2 \mathrm{~min}$. Each pan of eggs was then rinsed with lake water and placed into the appropriate egg bag $(7 \mathrm{~mm}$ or $19 \mathrm{~mm})$ filled with 11.4 liters of lake water before being transported to Blue Dog State Fish Hatchery (Waubay, SD). Transport time varied between 1.5 and 2.5 hours, but both treatments experienced the same daily transport duration.

In 2018, the same procedures were followed as in 2017 for both egg depth treatments with the exception of both sets of gametes being collected from Mid-Lynn Lake. Semen was collected and extended on April 30 and egg collection and fertilization occurred on May 1, 2 and 3. Because ice out was later in 2018, many females had already spawned a portion of their eggs; thus, the number of females per pan increased to 3.5 to reach a $19 \mathrm{~mm}$ depth and 2.0 females for the $7 \mathrm{~mm}$ depth.

\subsection{Egg Incubation and Survival}

At the hatchery, eggs were kept separated by treatment by placing 900 to $1200 \mathrm{ml}$ of eggs into McDonald jars (Pentair Aquatic Eco-Systems, Inc. Apopka, FL) that received a continuous supply of filtered well water (total hardness $=506 \mathrm{mg} / \mathrm{L} \mathrm{CaCO}_{3}$; alkalinity $=264$ $\mathrm{mg} / \mathrm{L} \mathrm{CaCO} ; \mathrm{pH}=7.5$; total dissolved solids $=612 \mathrm{mg} / \mathrm{L}$; dissolved oxygen $=90 \%$ saturation). Four to six jars were used for each treatment per day depending upon the number of eggs. All eggs received daily, prophylactic formalin $(1667 \mathrm{mg} / \mathrm{L}$ for $15 \mathrm{~min})$ treatments until hatching began. During 2017, eggs were incubated on $10.7{ }^{\circ} \mathrm{C}$ well water until May 3 when water temperature was raised to $13.7^{\circ} \mathrm{C}$ to accelerate hatching, which began on May 4 and lasted until May 9 for the latest fertilized eggs. Beginning on day 17 of incubation, unviable eggs were siphoned daily and the volume $(\mathrm{ml})$ removed was recorded for each treatment until all viable eggs had hatched. In 2018, initial water temperature was $10.7{ }^{\circ} \mathrm{C}$, but was increased to $13.7^{\circ} \mathrm{C}$ on May 4 because stocking locations were warming quickly due to a warmer weather pattern than experienced in 2017. Siphoning of unviable eggs began on day 12 of incubation and ended when all viable eggs had hatched on May 17. The total volume $(\mathrm{ml})$ of unviable eggs removed for each treatment was subtracted from the initial egg volume for that treatment to determine egg survival for each day. 


\subsection{Statistical Tests}

A Chi-Square test was used to determine whether frequency counts of unviable and viable egg volumes were distributed equally across egg depths of 7 and $19 \mathrm{~mm}$. Female walleye total length within treatments was not normally distributed, so comparisons between treatments were made using a non-parametric Mann-Whitney U test. Statistical significance was set at $P<0.05$.

\section{Results and Discussion}

The percentage of viable eggs by day ranged from $13.4-58.6 \%$ for $7 \mathrm{~mm}$ depth eggs and 6.4 $-57.9 \%$ for $19 \mathrm{~mm}$ depth (Figure 1). The percent volume of viable eggs fertilized at a depth of $7 \mathrm{~mm}$ was significantly higher than the volume at $19 \mathrm{~mm}$ during 4 of 6 days $\left(\chi^{2}=7.287\right.$ to 345.679; $P=<0.001$ to 0.007 ; Figure 1). Egg viability was not significantly different between the two depths the other two days which both occurred in $2017\left(\chi^{2}=0.118\right.$ to $0.488 ; P=0.488$ to 0.731 ; Figure 1).

Our findings are generally consistent with Moore (2003) who described a negative relationship between egg depth and fertility with the percent of fertile eggs being highest when fertilized at $4 \mathrm{~mm}$ and lowest at $10 \mathrm{~mm}$ for standard volumes of eggs. However, egg volume in the $7 \mathrm{~mm}$ and $19 \mathrm{~mm}$ depths was not standardized in our study. Pans in the current study resulted in the $19 \mathrm{~mm}$ treatment containing 2.7 times more egg volume than the $7 \mathrm{~mm}$ treatment. This implies that enhanced egg survival in the $7 \mathrm{~mm}$ treatment resulted from a lower volume of eggs; specifically, a higher ratio of sperm to eggs. Similarly, Rinchard et al. (2005) found fertilization success of walleye eggs to be affected by the sperm to egg ratio and recommended a 25 000:1 sperm to egg ratio to attain $70 \%$ survival to the eyed stage. Although we did not quantify the sperm to egg ratio at our $7 \mathrm{~mm}$ depth, it undoubtedly was higher than 25 000:1 and most likely contributed to the improved egg survival. A logarithmic relationship between sperm cell density and fertilization success was reported by Casselman et al. (2006) with the highest rate of fertilization occurring at $500000 \mathrm{sperm} / \mathrm{ml}$ and lowest at $500 \mathrm{sperm} / \mathrm{ml}$. In our study, sperm cell density and quality were presumed to be the same between treatments and not contributing factors to the differences observed in egg survival. All flasks of extender were made with semen from five males, checked for motility prior to use, and used within 3 days of collection which is well within the 14-d window before sperm viability decreases (Moore, 1996). Lack of a significant difference in two of the six comparisons could be attributed to the variable survival that walleye eggs exhibit (Moore, 2003). The majority of the time, though, walleye egg survival was enhanced by the reduced egg depth during fertilization. 


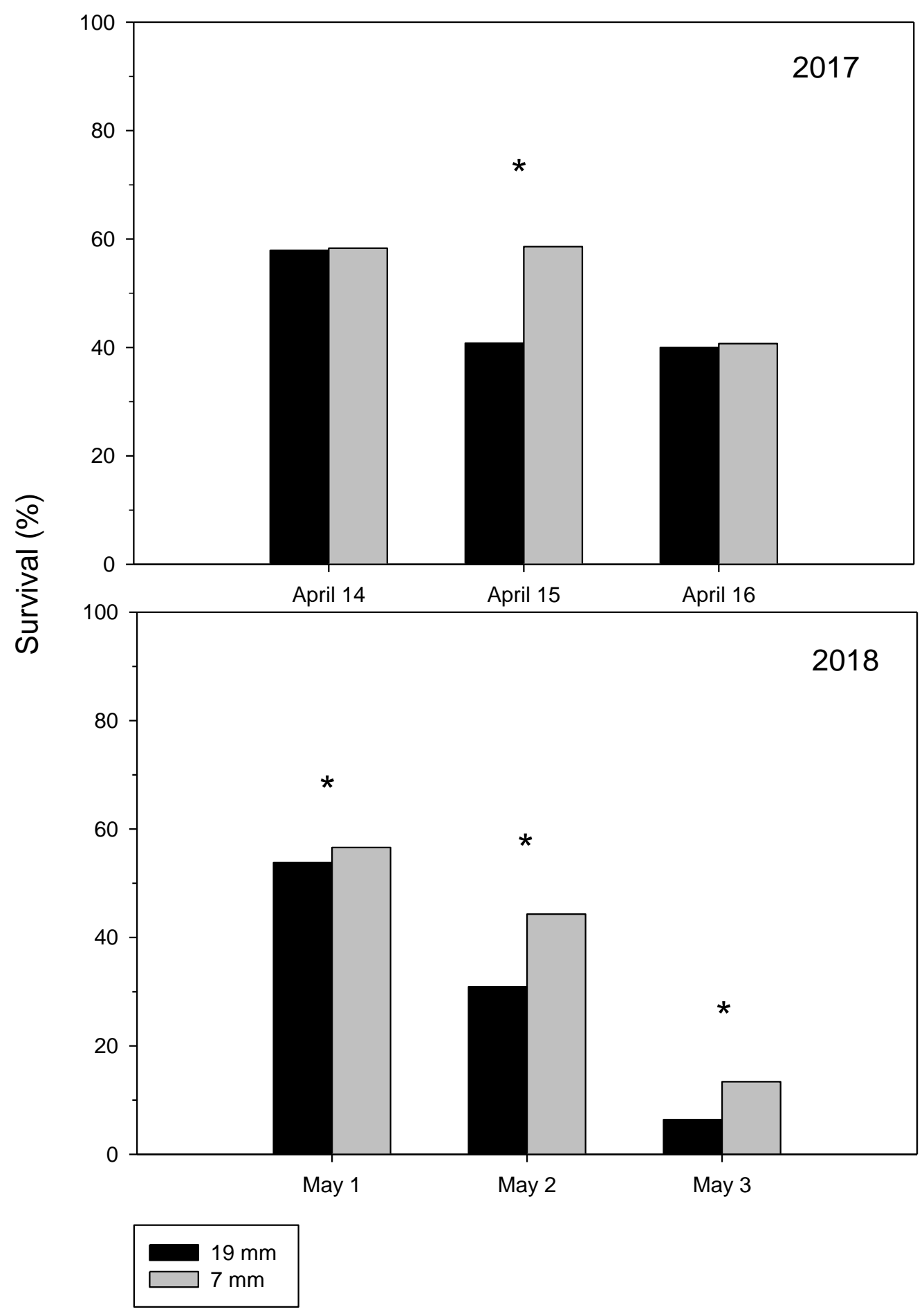

Figure 1. Survival of walleye eggs fertilized at an egg depth of 7 or $19 \mathrm{~mm}$ in standard pans during three days of the 2017 and 2018 spawning seasons. Dark bars represent percent survival at $19 \mathrm{~mm}$ depth and light bars are $7 \mathrm{~mm}$ depth. An asterisk indicates a significant difference $(P<0.05)$ in survival between egg depth treatments for that day

Total length of spawned female walleye varied between 445 and $762 \mathrm{~mm}$ (Table 1) and was not significantly different between egg depths on any day in 2017 (Test Stat $=9.5$ to 63.0, $P=$ 
0.17 to 0.62 ). Similarly, female length varied from 483 to $711 \mathrm{~mm}$ (Table 1) and was not significantly different between egg depths on any day in 2018 (Test Stat $=21.0$ to 62.0, $P=$ 0.52 to 0.84 ). We do not believe the results were influenced by female walleye size. Variation in egg quality due to potential maternal effects was considered to be distributed equally among the egg depth treatments.

Table 1. Median (min, max) total length $(\mathrm{mm})$ for female walleye that were spawned for each egg depth treatment during three days of the spawning season in both 2017 and 2018 on Mid-Lynn Lake, South Dakota. No significant differences in total length were detected between treatments on any day $(P=0.17$ to 0.84$)$

Female Walleye Total Length (mm)

\begin{tabular}{lccc}
\hline 2017 & April 14 & April 15 & April 16 \\
\cline { 2 - 4 } $7 \mathrm{~mm}$ & $572(445,673)$ & $635(457,692)$ & $622(470,699)$ \\
$19 \mathrm{~mm}$ & $662(495,699)$ & $667(508,762)$ & $648(482,711)$ \\
\hline 2018 & May 1 & May 2 & May 3 \\
$7 \mathrm{~mm}$ & $622(584,689)$ & $552(483,692)$ & $549(483,641)$ \\
$19 \mathrm{~mm}$ & $647(485,711)$ & $520(495,711)$ & $559(476,711)$ \\
\hline
\end{tabular}

Although the $7 \mathrm{~mm}$ depth resulted in higher egg survival percentages than the $19 \mathrm{~mm}$ depth, the highest percent survival remained 10 to $30 \%$ lower than many previous reports. Despite a lower egg volume in the $7 \mathrm{~mm}$ treatment $(392 \mathrm{~mL})$ and similar application of the extended semen, the highest survival through hatch did not achieve $60 \%$. Others have reported survival through hatching of greater than 65\% (Bennett and Melby, 1996; Moore, 2003). It is possible that low egg quality, such as over-ripeness, may have reduced survival in both treatments. Egg survival declined over time in both treatments and was especially evident in 2018 when survival below $20 \%$ was observed on the final day. During 2018, ice out did not occur until the end of April which resulted in a short and late spawning season for South Dakota (Summerfelt et al., 2011). Perhaps the late spawning season caused eggs to become overripe, especially as the season progressed as it was noted in 2018 that several females had already spawned some eggs before the remaining were manually stripped. Walleye eggs are considered to take an intermediate amount of time to overripen with successful fertilization and development of eggs that were stored for 24 hours post ovulation (Johnston et al., 2008). Although slight changes in storage temperature (Rinchard et al., 2005) and individual female variation in rates of egg deterioration post ovulation can reduce fertilization success in walleye (Johnston et al., 2008). 


\section{Summary and Conclusions}

Reducing egg depth from 19 to $7 \mathrm{~mm}$ during fertilization enhanced egg survival through hatch during four of the six days of egg collection. This most likely occurred through the increased ratio of sperm to egg resulting in increased fertility. Overall lower egg survival than previous reports suggest that factors other than egg depth during fertilization need to be investigated in South Dakota. Future research should consider sperm distribution and amount during fertilization as sperm cell movement can be limited to less than $5 \mathrm{~mm}$ after activation (Casselman et al., 2006).

\section{Acknowledgement}

This study was completed with assistance and expertise provided by many South Dakota Department of Game, Fish and Parks employees including Jerry Broughton, Randy Smidt, Ryan Rasmus, Nathan Pool, Chad Haabala, Mark Ermer, Todd Kaufman, Tyrel Moos, Steve Kennedy, and Ryan Braun.

\section{References}

Bennett, C. D., \& Melby, J. L. (1996). Walleye spawning operations at Bonny Reservoir, Colorado. In R.C. Summerfelt (Ed.), Walleye Culture Manual (pp. 19-20). NCRAC Culture Series 101. North Central Regional Aquaculture Center Publications Office, Iowa State University, Ames.

Casselman, S. J., Schulte-Hostedde, A. I., \& Montgomerie, R. (2006). Sperm quality influences male fertilization success in walleye (Sander vitreus). Canadian Journal of Fisheries and Aquatic Sciences, 63, 2119-2125. https://doi.org/10.1139/f06-108

Colesante, R. T. (1996). Collection of walleye broodstock, egg take, incubation, and fry production at the Oneida Fish Cultural Station. In R.C. Summerfelt (Ed.), Walleye Culture Manual (pp. 71-74). NCRAC Culture Series 101. North Central Regional Aquaculture Center Publications Office, Iowa State University, Ames.

Copeland, J. A., \& Wolgamood, M. M. (1996). Walleye spawning in Michigan. In R.C. Summerfelt (Ed.), Walleye Culture Manual (pp. 21-23). NCRAC Culture Series 101. North Central Regional Aquaculture Center Publications Office, Iowa State University, Ames.

Johnston, T. A., Kaufman, S. D., Moles, M. D., Wiegand, M. D., \& Leggett, W. C. (2008). Effects of delayed fertilization on embryo viability in walleye Sander vitreus (Mitchill): the role of maternal effects. Journal of Fish Biology, 72, 2634-2644. https://doi.org/10.1111/j.1095-8649.2008.01879.x

Longmire, C. L. (2019). Report of Results: 2017 South Dakota Angler Survey. Pierre, SD: South Dakota Game, Fish and Parks.

Moore, A. (1996). Use of semen extenders for walleye. In R.C. Summerfelt (Ed.), Walleye Culture Manual (pp. 51-53). NCRAC Culture Series 101. North Central Regional Aquaculture Center Publications Office, Iowa State University, Ames. 


\section{Macrothink}

Moore, A. A. (2003). Manipulation of fertilization procedures to improve hatchery walleye egg fertility and survival. North American Journal of Aquaculture, 65, 56-59. https://doi.org/10.1577/1548-8454(2003)065<0056:MOFPTI>2.0.CO;2

Rinchard, J., Dabrowski, K., Van Tassell, J. J., \& Stein, R. A. (2005). Optimization of fertilization success in Sander vitreus is influenced by the sperm:egg ratio and ova storage. Journal of Fish Biology, 67, 1157-1161. https://doi.org/10.1111/j.0022-1112.2005.00800.x

Summerfelt, R. C., Johnson, J. A., \& Clouse, C. P. (2011). Culture of walleye, sauger, and hybrid walleye. In B.A. Barton (Ed.), Biology, Management, and Culture of Walleye and Sauger (pp.451-570). American Fisheries Society, Bethesda, Maryland.

Sweet, B. (2017). Walleye spawning: fish length versus percent eye-up. Coolwater fish culture workshop, South Bend, Indiana. Abstract only.

\section{Copyrights}

Copyright for this article is retained by the author(s), with first publication rights granted to the journal.

This is an open-access article distributed under the terms and conditions of the Creative Commons Attribution license (http://creativecommons.org/licenses/by/4.0/) 